Article

\title{
Effects of High-Temperature Exposure on the Mechanical Properties of Kenaf Composites
}

\author{
Nabilah Afiqah Mohd Radzuan 1,*(D), Dulina Tholibon 1,2, Abu Bakar Sulong 1,*, \\ Norhamidi Muhamad ${ }^{1}$ and Che Hassan Che Haron ${ }^{1}$ \\ 1 Department of Mechanical and Manufacturing Engineering, Faculty of Engineering and Built Environment, \\ Universiti Kebangsaan Malaysia, Bangi 43600, Selangor, Malaysia; dulina@gmail.com (D.T.); \\ norhamidi@ukm.edu.my (N.M.); chase@ukm.edu.my (C.H.C.H.) \\ 2 Department of Mechanical Engineering, Politeknik Merlimau, KB 1031, Pejabat Pos Merlimau, \\ Merlimau 77300, Melaka, Malaysia \\ * Correspondence: afiqah@ukm.edu.my (N.A.M.R.); abubakar@ukm.edu.my (A.B.S.); \\ Tel.: +603-89217190 (A.B.S.)
}

Received: 22 May 2020; Accepted: 22 June 2020; Published: 23 July 2020

\begin{abstract}
Automotive parts, including dashboards and trunk covers, are now fabricated through a compression-molding process in order to produce lightweight products and optimize fuel consumption. However, their mechanical strength is not compromised to avoid safety issues. Therefore, this study investigates kenaf-fiber-reinforced polypropylene composites using a simple combing approach to unidirectionally align kenaf fibers at $0^{\circ}$. The kenaf composite was found to withstand a maximal temperature of $120^{\circ} \mathrm{C}$. The tensile and flexural strengths of the aligned kenaf composites (50 and $90 \mathrm{MPa}$, respectively) were three times higher than those of the commercialized Product $\mathrm{T}$ (between 39 and $30.5 \mathrm{MPa}$, respectively) at a temperature range of 90 to $120{ }^{\circ} \mathrm{C}$. These findings clearly showed that the mechanical properties of aligned kenaf fibers fabricated through the combing technique were able to withstand high operating temperatures $\left(120^{\circ} \mathrm{C}\right)$, and could be used as an alternative to other commercial natural-fiber products.
\end{abstract}

Keywords: fibers; mechanical properties; mechanical testing; compression molding

\section{Introduction}

Sustainability and ecofriendliness are the current main criteria for manufacturing products [1]. Composite materials, therefore, seem suitable to fulfilling the requirements for producing ecofriendly products, given that the mechanical properties of these materials are easily customized to manufacturers' needs [2,3]. However, commonly applied composite materials, including glass- and carbon-reinforced polymer, are nonbiodegradable, with high processing costs and the need to comply with environmental legislation, limiting their application and use [1,4]. Given these limitations, natural fibers, known as biocomposites, were introduced as an alternative to existing composite materials because they offer good biodegradability, low density, and they have adequate mechanical properties [5]. International automotive manufacturers have incorporated these natural fibers into most manufactured automotive parts, allowing $80 \mathrm{wt} \%$ of waste to be recycled and reused [1,6]. However, none of these biocomposites is available for high-temperature products, given that natural fibers are usually unstable at temperatures above $100{ }^{\circ} \mathrm{C}$, thus reducing the strength of the composites by around $10 \%$ every $10 \mathrm{~min}[7,8]$.

This study proposes that the kenaf fiber, as a biodegradable material in conjunction with a conventional manufacturing process, can withstand operating temperatures as high as $120^{\circ} \mathrm{C}$. Kenaf stems consist of bast and core fibers known as kenaf fibers. Bast and core fibers exhibit a strength of 20 to $230 \mathrm{MPa}$ with an average density of $1.45 \mathrm{~g} / \mathrm{cm}^{3}$, while the kenaf fiber itself can reach a maximal tensile 
strength of $930 \mathrm{MPa}$ [9-11]. However, the main drawback of using kenaf fibers is their hydrophilic nature, as they cannot be mixed with the hydrophobic polymer matrix given the issues surrounding their adhesion qualities $[12,13]$. Hence, the researchers of this study tried to address and overcome this issue, including by using a surface treatment of $4 \mathrm{wt} \%$ of $\mathrm{NaOH}$, which improved their mechanical properties by $78 \%[10,14]$. Previous studies demonstrated that, by using kenaf-fiber-reinforced epoxy resin and aligning the fibers in a particular direction $\left(0^{\circ}\right.$ to $\left.90^{\circ}\right)$, their mechanical properties could be improved without using any surface treatment. Moreover, by diminishing the surface-treatment procedure, a more affordable and time-effective manufacturing process could be introduced [15].

Meanwhile, in the conventional manufacturing process, industries often use either injection-or compression-molding techniques to fabricate composite mixtures [16]. However, those techniques result in randomly oriented kenaf fibers, which further reduces their mechanical properties, with an average strength of $30 \mathrm{MPa}$ [17]. Currently, natural composites are often used as an interior part, in which their mechanical properties can be compromised. However, recent studies have indicated that, through certain processes, these mechanical properties can be improved. Hence, these processes can be implemented elsewhere, for example, in dashboard panels and trunk covers. Prior research exhibited that adapting the compression-molding process aids in developing an aligned kenaf composite [18]. Thus, it strengthens the mechanical properties of kenaf composites, as its performance can be altered according to manufacturers' needs. However, the main concern in using kenaf composites in dashboard or trunk covers is their ability to withstand high temperatures (above $60^{\circ} \mathrm{C}$ ). Thus, in addition to fabricating the kenaf composite through a compression-molding process, a discussion on fiber orientation was also crucial, as it has consequent effects on the composite's mechanical strength. The importance of fiber orientation was also supported by previous studies in which composite materials that exhibited desirable mechanical properties were dependent on composite structure and orientation angle $[8,19]$. Therefore, on this basis, orientation studies were conducted by the researchers of this study to enhance the mechanical properties of kenaf composites, especially under high-temperature operations. Some studies also indicated that the fiber orientation of composite materials frequently results in warpage, which degrades their mechanical performance as temperatures increase $[20,21]$. Hence, this study focused on the effect of temperatures ranging from 30 to $120{ }^{\circ} \mathrm{C}$ on the different orientations of kenaf-reinforced polypropylene (PP) composites.

\section{Methodology}

\subsection{Materials}

Kenaf fibers (bast), as shown in Figure 1a, had an average length between 350 and $400 \mathrm{~mm}$, and were supplied by Lembaga Kenaf dan Tembakau Negara (LKTN, Kelantan), Malaysia. This type of kenaf was selected on the basis of its ability to exhibit excellent mechanical properties without requiring to undergo an alkaline-chemical-treatment process [21]. Details on the chemical composition of the kenaf fibers are listed in Table 1 . The thermoplastic polymer used in this study was polypropylene, grade Titan-600, in powder form with an average size of $90 \mu \mathrm{m}$, a density of $910 \mathrm{~kg} / \mathrm{m}^{3}$, and a melting temperature of $160^{\circ} \mathrm{C}$. It was supplied by Goonvean Fibres Ltd., England, UK. 


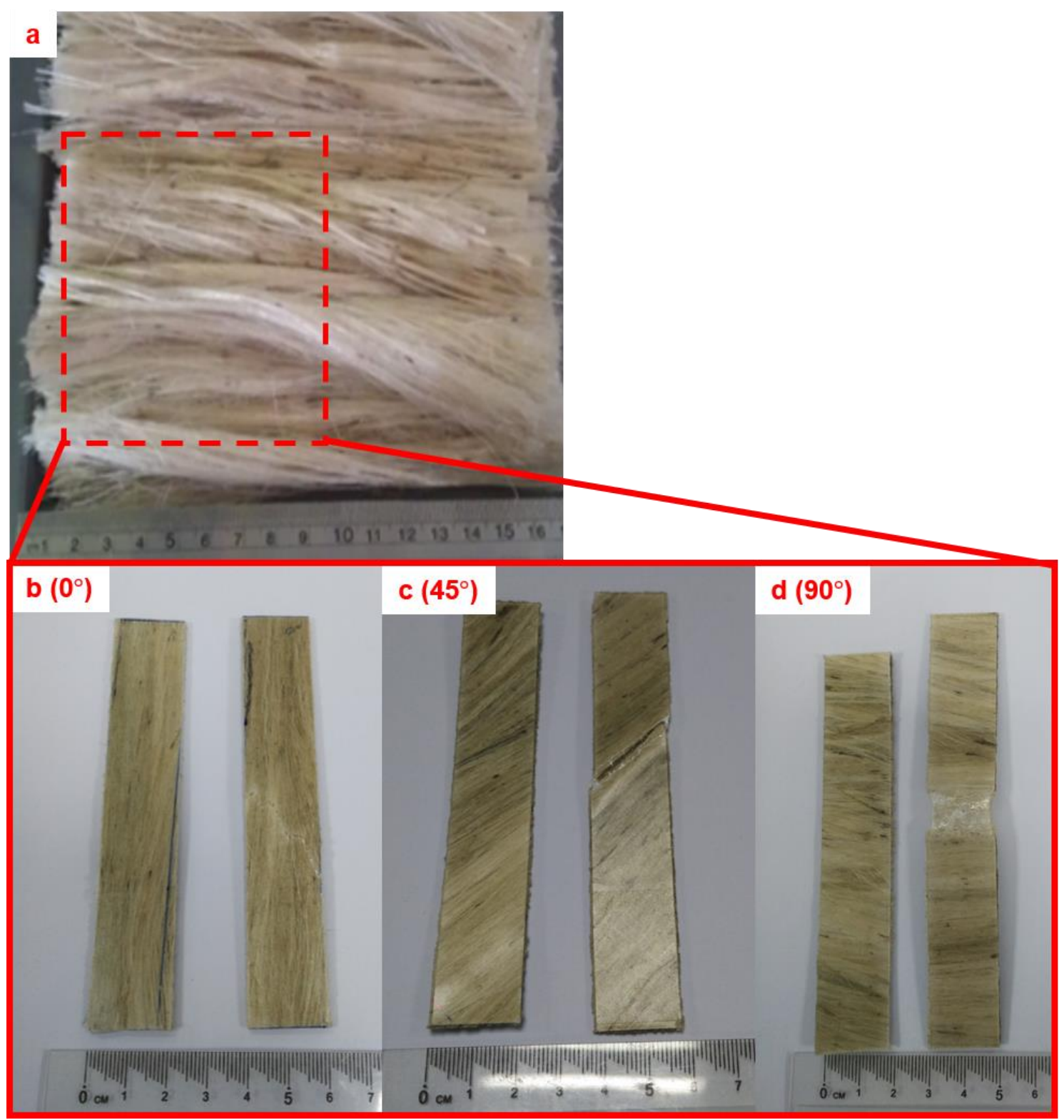

Figure 1. (a) Kenaf fibers supplied by Lembaga Kenaf dan Tembakau Negara (LKTN), as received. Kenaf composite at different orientation angles of (b) $0^{\circ}$, (c) $45^{\circ}$, and (d) $90^{\circ}$.

Table 1. Composition of kenaf fibers.

\begin{tabular}{ll}
\hline Composition & Percentage (\%) \\
\hline Extractive & 5.88 \\
Holocellulose (cellulose +hemicellulose) & 96.17 \\
$\alpha$-Cellulose & 61.02 \\
Hemicellulose & 35.15 \\
Lignin & 12.5 \\
\hline
\end{tabular}

\subsection{Fabrication Process}

The kenaf bast fibers initially underwent a water-retting process for 7 to $10 \mathrm{~h}$ to separate the outer layer (bast) from the inner layer (core), ensuring that the kenaf-fiber surface was clean of any impurities. The water-retting process enhances the surface roughness of the kenaf fiber, which aids in the adhesion of polymer resin onto its surface [22]. The kenaf bast fibers were later combed, which indirectly removed any physical impurities on the kenaf fibers' surface, to ensure that the fibers would be long, 
smooth, and continuous before drying in an oven at $40{ }^{\circ} \mathrm{C}$ for $24 \mathrm{~h}$. The prepared kenaf fibers were then cut into $175 \mathrm{~mm}$ long pieces/strips, and aligned on $0^{\circ}, 45^{\circ}$ and $90^{\circ}$ angles before being placed in the hot-press mold $(175 \times 175 \times 2 \mathrm{~mm})$, as shown in Figure $1 \mathrm{~b}-\mathrm{d}$. The kenaf fibers were then sandwiched together with the polypropylene powder; $40 \mathrm{wt} \%$ of kenaf and $60 \mathrm{wt} \%$ of polypropylene were used. After that, the prepared materials underwent a compression-molding process using a 50 ton hot-press machine at a pressing temperature between 190 and $210{ }^{\circ} \mathrm{C}$, and with applied pressure between 5 and $10 \mathrm{MPa}$ for between 2 and $6 \mathrm{~min}$.

\subsection{Characterization}

The obtained samples were then cut into pieces with a width of $20 \mathrm{~mm}$, a length of $115 \mathrm{~mm}$, and a thickness of $2 \mathrm{~mm}$ for the tensile test based on ASTM D638-99. The tensile test was conducted using the Zwick $30 \mathrm{kN}$ AllroundLine attached to a tube furnace, with the temperature set at 30, 60, 90 , and $120^{\circ} \mathrm{C}$, respectively. Next, the flexural-strength test was conducted using the Zwick $30 \mathrm{kN}$ with a speed of $2 \mathrm{~mm} / \mathrm{min}$. The dimensions of the sample were $70 \times 20 \times 2 \mathrm{~mm}$ based on ASTM D790-99 for this specific test. Both the tensile and flexural tests were performed using 10 sets of samples. Dynamic mechanical analysis (DMA) was performed using the PerkinElmer DMA 8000 machine at room temperature until a temperature of $150{ }^{\circ} \mathrm{C}$ was reached. This test required the samples' dimensions to be $30 \times 10 \times 2 \mathrm{~mm}$ based on the ASTM D5023 standard, with the heat rate set at $2{ }^{\circ} \mathrm{C} / \mathrm{min}$, and with the frequency set at $1 \mathrm{~Hz}$. Unlike with the DMA test, Poisson's ratio was determined using a Kyowa CC-33A and a PCD 300 Series sensor surface on the basis of ASTM D638-99. Poisson's ratio was then monitored using the PCD 300B software that was attached to the Zwick $30 \mathrm{kN}$ AllroundLine machine. A total of five samples were used for each conducted test. Poisson's ratio was measured on the basis of the Young's modulus and shear modulus using Equation:

$$
v=\frac{E}{2 G}-1,
$$

where $v$ is Poisson's ratio, $E$ is Young's modulus, and $G$ is the shear modulus [23].

\section{Results and Discussion}

Figure 2 illustrates the tensile strength of pure PP and kenaf/PP composites at different orientation angles between $0^{\circ}$ and $90^{\circ}$ as temperature was increased from 30 to $120^{\circ} \mathrm{C}$. The study found that, as temperature increased, both the kenaf/PP composites and the polypropylene tended to deteriorate, which is explained by polypropylene's nature, given that it began to experience an unstable chain as the temperature reached $100{ }^{\circ} \mathrm{C}$ [24]. By comparison, the kenaf/PP composites experienced an unstable structure when the temperature increased above $80{ }^{\circ} \mathrm{C}[25,26]$. As shown in Figure 2, at the temperature range of 60 to $120^{\circ} \mathrm{C}$, the kenaf/PP composites were able to achieve a maximal tensile strength that ranged from 70 to $90 \mathrm{MPa}$, which is sufficient for automotive parts (e.g., a trunk cover or dashboard) that require a tensile strength of around $30 \mathrm{MPa}[2,15]$. These findings indicated that kenaf/PP composites are appropriate to be used, given that the applied temperature $\left(60\right.$ to $\left.120^{\circ} \mathrm{C}\right)$ was near that of other commercial composite products used in high-temperature applications that can offer better mechanical properties [18]. Furthermore, Figure 2 demonstrates that, as the orientation angle increased from $0^{\circ}$ to $45^{\circ}$ and $90^{\circ}$, tensile strength dropped dramatically, from $\sim 90$ to $\sim 20 \mathrm{MPa}$, even though theoretically, the fibers being aligned in one direction within the composite materials should enhance their mechanical properties $[7,27]$. This phenomenon occurred because, as the fibers were oriented to align with the applied load, the inner fiber layer was damaged, resulting in their mechanical properties being lowered, as shown in Figure 3a [28,29]. 


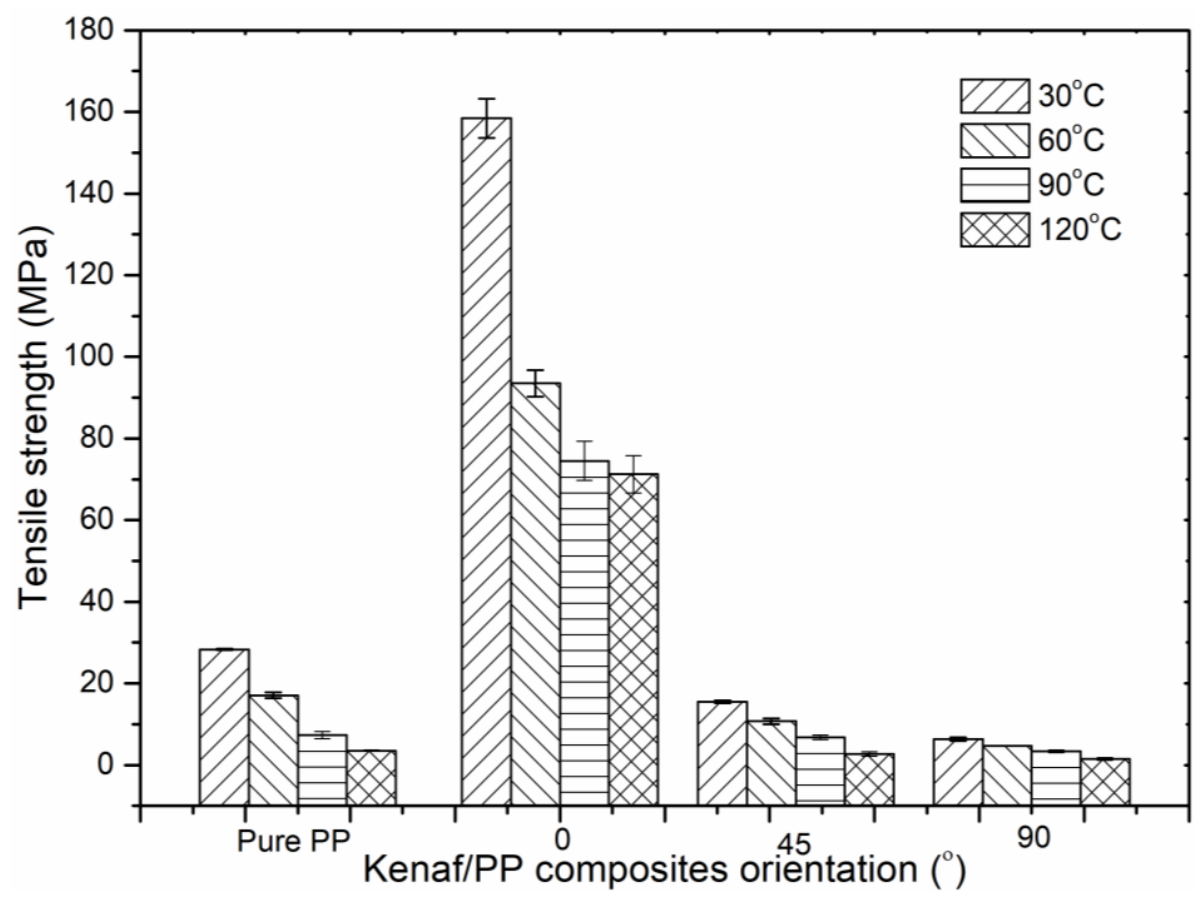

Figure 2. Tensile strength of kenaf/polypropylene (PP) composites at different orientation angles and temperatures.
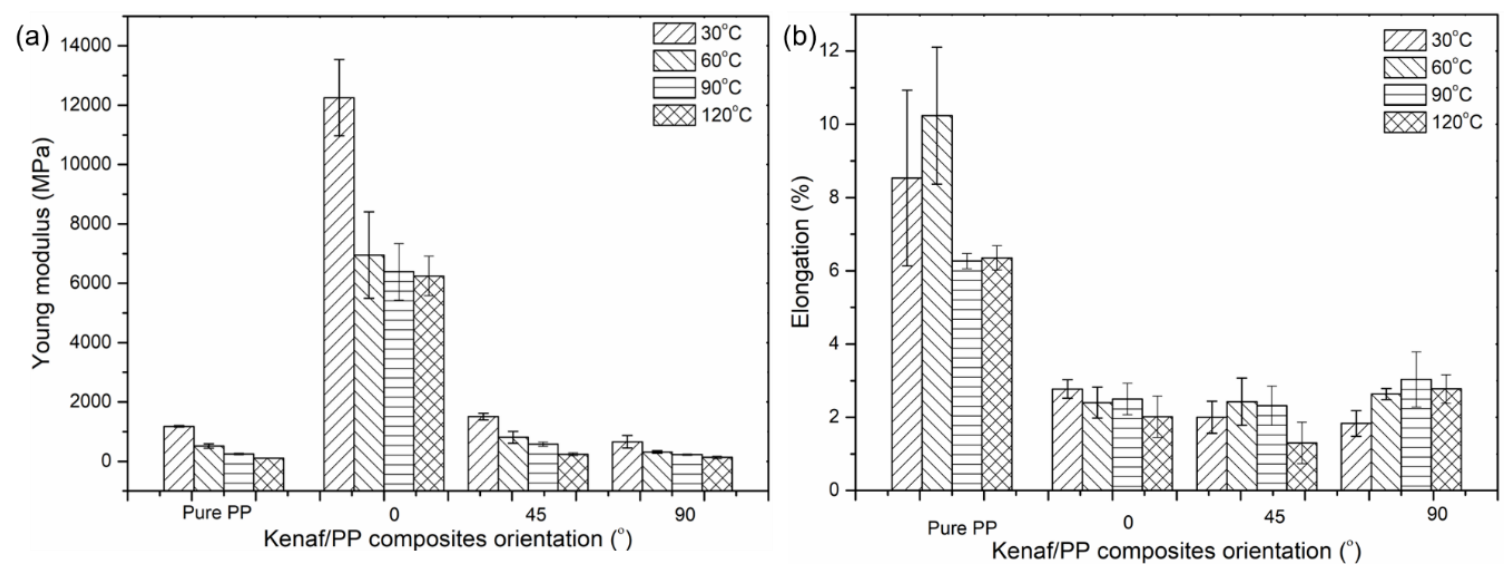

Figure 3. (a) Young's modulus and (b) elongation of kenaf/polypropylene (PP) composites at different orientation angles and temperatures.

Theoretically, the aligned fibers that were perpendicular to the applied load required higher loading before the composite structure began to fail [30,31]. In contrast, the aligned fibers that were parallel showed a lower applied load resulting in fiber breakage [30,32]. This can easily be seen in Figure $1 c, d$, in which the failures obviously occurred and propagated along the kenaf fibers at orientation angles of $45^{\circ}$ and $90^{\circ}$. This explains why the kenaf/PP composites that were aligned at $0^{\circ}$ perpendicular to the applied load were able to sustain excellent tensile strength until $160 \mathrm{MPa}$ compared to the kenaf fibers aligned at $45^{\circ}$ and $90^{\circ}$. Moreover, previous studies suggested that, at an orientation angle of $0^{\circ}$, kenaf/PP composites possessed a much longer kenaf fiber structure due to minimal fiber breakage, thereby aiding in strengthening the composite structure by homogenously distributing the load [24,33,34]. Unlike with the fiber orientations of $45^{\circ}$ and $90^{\circ}$, more kenaf fiber breakage was experienced, given the localized applied load that weakened the strength of the composite $[35,36]$. Lower tensile strength was also recorded for the pure PP when compared to the aligned kenaf/PP 
composites at $0^{\circ}$ because of the existence of the aligned kenaf fibers, which strengthened the overall structure of the composite [35].

A similar trend can also be seen in Figure 3a, where the Young's modulus of kenaf/PP composites appeared to decrease as temperature increased. In fact, some studies reported that the drop experienced by the kenaf/PP composites was mainly due to the warpage that occurred on the composite surface resulting from the crystallization of the polymer structure, causing brittleness $[37,38]$. Therefore, this could affect the mechanical properties of the kenaf/PP composites at temperatures above $60{ }^{\circ} \mathrm{C}$ [39]. Figure $3 \mathrm{~b}$ shows that the elongation of kenaf/PP composites resulted in no significant change as temperature increased. Additionally, the orientation of the fibers did not affect the elongation of the kenaf/PP composites, with the average elongation recorded at $2.5 \%$. However, this slightly differed from the elongation results obtained for the pure PP, where the most elongation was recorded at an average of $10 \%$. These findings support the Young's modulus and tensile-strength results, indicating that the kenaf/PP composites exhibited greater stiffness compared to that of pure PP [40].

Figure 4 illustrates the flexural strength of kenaf/PP composites, where the highest flexural strength was recorded as $105 \mathrm{MPa}$ at $30^{\circ} \mathrm{C}$. However, as temperature increased to $120^{\circ} \mathrm{C}$, flexural strength began to decrease until reaching an average of $70 \mathrm{MPa}$. The same trend was recorded for pure PP, where flexural strength decreased as temperature increased. However, flexural strength recorded for the kenaf/PP composites was three times higher than that of the pure PP, at an average of $40 \mathrm{MPa}$. A similar trend was also observed in the flexural-modulus results, where the kenaf/PP composites exhibited excellent flexural strength and flexural modulus compared to pure PP. Past studies reported that the common flexural strength and flexural modulus recorded for a kenaf-composite-reinforced epoxy resin were, on average, 180 and $15 \mathrm{MPa}$, respectively $[7,23]$. Studies have also shown that the mechanical properties of fabricated aligned $\left(0^{\circ}\right) \mathrm{kenaf} / \mathrm{PP}$ composites at a temperature of $120^{\circ} \mathrm{C}$ exceeded those of commercial products (Product T). Detailed results of the comparison between fabricated composites $\left(0^{\circ}\right.$ orientation angle) and commercial products are listed in Table 2 . Therefore, on this basis, the outstanding mechanical properties of kenaf/PP composites were comparable to those of commercial products, and have much to offer given their potential to withstand high-temperature operations while maintaining recyclability [41].

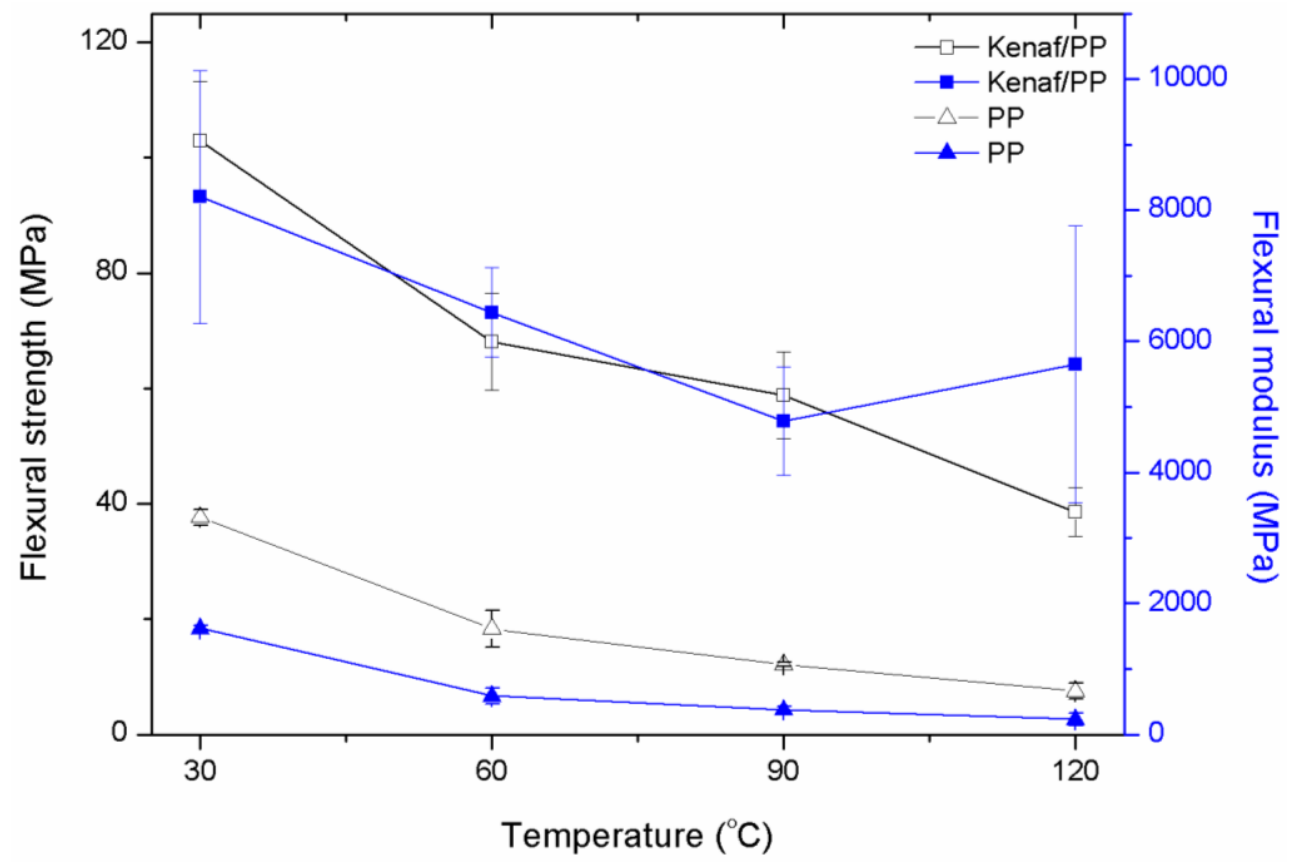

Figure 4. Flexural strength and flexural modulus of kenaf/PP composites at different temperatures. 
Table 2. Comparison of mechanical properties of fabricated kenaf/PP composites and Product $\mathrm{T}$ at $120{ }^{\circ} \mathrm{C}$.

\begin{tabular}{lll}
\hline Mechanical Properties & Kenaf/PP $\left(\mathbf{0}^{\circ}\right)$ at $\mathbf{1 2 0}{ }^{\circ} \mathbf{C}$ & Product $\mathbf{T}$ \\
\hline Tensile strength $(\mathrm{MPa})$ & $\sim 90$ & 30.52 \\
Flexural strength $(\mathrm{MPa})$ & $\sim 50$ & 39.4 \\
Young's modulus $(\mathrm{GPa})$ & $\sim 7.5$ & 2.56 \\
Flexural modulus $(\mathrm{GPa})$ & $\sim 6.0$ & 4.51 \\
\hline
\end{tabular}

The flexural strength and flexural modulus of the kenaf/PP composites at different orientation angles and room-temperature conditions are displayed in Figure 5. The aligned kenaf fibers at an orientation angle of $0^{\circ}$ demonstrated maximal flexural strength and flexural modulus of $110 \mathrm{MPa}$ and 8.5 GPa, respectively. Obtained results were six times greater than those of pure PP. Previous studies explained this result by reporting that, when kenaf fibers were aligned in a unidirectional position, they possessed the most stiffness because fiber efficiency was strong given that the fibers were able to contribute the same applied load [42]. On the other hand, when the kenaf fiber was oriented on $45^{\circ}$ and $90^{\circ}$ angles, both flexural strength and flexural modulus tended to deteriorate from 20 and $40 \mathrm{MPa}$ to 1 and $3 \mathrm{GPa}$, respectively, which was marginally higher compared to the obtained tensile strength. Therefore, on this basis, the orientation of kenaf fibers influenced the flexural strength of the composite material by retaining the maximal load being applied [43,44].

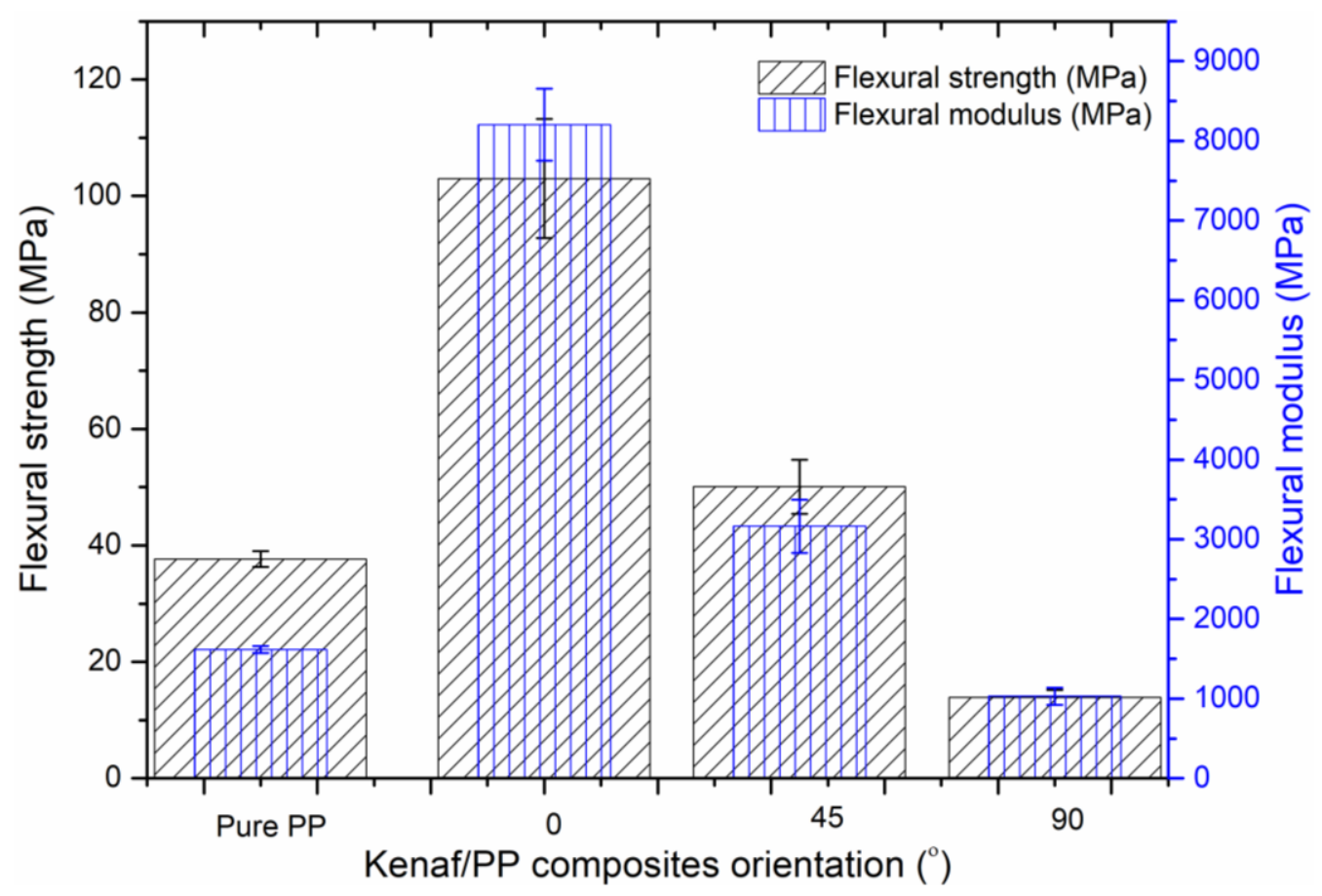

Figure 5. Flexural strength and flexural modulus of kenaf/polypropylene (PP) composites at different orientation angles at temperature of $120^{\circ} \mathrm{C}$.

The effects of fiber orientation and temperature changes were determined on the basis of DMA results, given that they provided information about the materials' strength and brittleness related to the storage modulus, while tan $\delta$ (Figure 6a2) identified its elasticity behavior [45]. Figure 6a1 shows that the maximal storage modulus of $120 \mathrm{MPa}$ was recorded at an orientation angle of $90^{\circ}$, followed by $80 \mathrm{MPa}$ at $0^{\circ}$. This phenomenon was due to the kenaf composite at $90^{\circ}$ behaving like an elastic material that stored more energy and less strength compared to the aligned kenaf composite at $0^{\circ}$. Meanwhile, for kenaf/PP composites at $45^{\circ}$, the storage modulus indicated the extreme energy loss contributed to the direction of the kenaf fibers, which were unable to withstand excessive amounts of 
energy. A similar negative trend was also shown in the kenaf/PP composites at $90^{\circ}$, which supported the lowest flexural strength recorded at a temperature of $120^{\circ} \mathrm{C}$. In addition, Figure $6 \mathrm{a} 2$ indicates that there were increments of $\tan \delta$ due to the increase in interface bonding among the kenaf/PP composites, which later reduced the damping factor because of the decrease in mobility of the molecular chains at the kenaf/PP composites' interface [45].These are shown in Figure $7 \mathrm{~b}, \mathrm{~b} 1$, in which at $90^{\circ}$, the adhesion between the kenaf fibers and the matrix was low, with no reinforcement within the kenaf fibers as the applied load was only subjected to the polymer matrix. In contrast, compared to the $90^{\circ}$ orientation of kenaf/PP composites, the composites at a $0^{\circ}$ orientation angle seemed to experience no misalignment, improper wettability, or any other defect which might deteriorate their mechanical performance, which was also reported by another study using similar kenaf/PP composites [46]. This was because the prepared kenaf fibers were combed rather than chemically treated, further resulting in a balanced mixture and excellent composite structure [46]. Furthermore, Figure 7a,a1 demonstrates that the kenaf fibers experienced a fiber pull-out due to strong adhesion within the kenaf fibers and matrix. However, increasing the temperature resulted in the kenaf composite behaving like a viscous material, leading to energy dissipation. This further resulted in higher stress being required to break the material bonding, which lowered its storage modulus. Prior research exhibited that kenaf fibers tend to experience $9.5 \%$ moisture evaporation at a temperature of $153{ }^{\circ} \mathrm{C}$, which was supported by these findings: as temperature increased to $120^{\circ} \mathrm{C}$, the bonding of the kenaf composite was weakened, as higher stress was required to break it [47]. Figure $6 \mathrm{~b}, \mathrm{~b} 1$ shows that, as the temperature exceeded $120^{\circ} \mathrm{C}$, kenaf fibers started to deteriorate and degrade, resulting in the composite bonding weakening. This explains the results that were obtained with an orientation angle of $0^{\circ}$, where at $100{ }^{\circ} \mathrm{C}$ (the melting temperature at which there was complete strength loss), the storage modulus was recorded at $40 \mathrm{MPa}$ compared to $35 \mathrm{MPa}$ for an orientation angle of $90^{\circ}$. The curve also illustrates that pure PP and kenaf/PP at an orientation angle of $45^{\circ}$ experienced no significant change, indicating that there is marginal difference in both of the materials' thermomechanical properties [23]. Compared to the pure kenaf fiber shown in Figure $6 \mathrm{~b}$, thermogravimetric analysis of kenaf/PP composites reported that, in the temperature range of 30 to $175{ }^{\circ} \mathrm{C}$, endothermic peaks appeared at $\sim 85^{\circ} \mathrm{C}$ [41]. Studies using similar kenaf/PP composites reported that exothermic peaks were recorded at the temperature of $250{ }^{\circ} \mathrm{C}$ due to the degradation and decomposition of cellulose at higher temperatures [41]. Furthermore, Figure 6 displays that the tan $\delta$ value increased as temperature increased. The maximal $\tan \delta$ value recorded at the $0^{\circ}$ orientation angle, 0.21 , indicated that the aligned kenaf fibers at $0^{\circ}$ exhibited a rigid composite structure (being nonthermoplastic). Indeed, this contrasted with the results obtained for pure PP, which were the lowest recorded at 0.05; this indicates that it is a purely elastic material. Therefore, on this basis, the dynamic mechanical behavior of kenaf/PP composites was dominated by the polypropylene resin rather than by kenaf fibers [23]. 

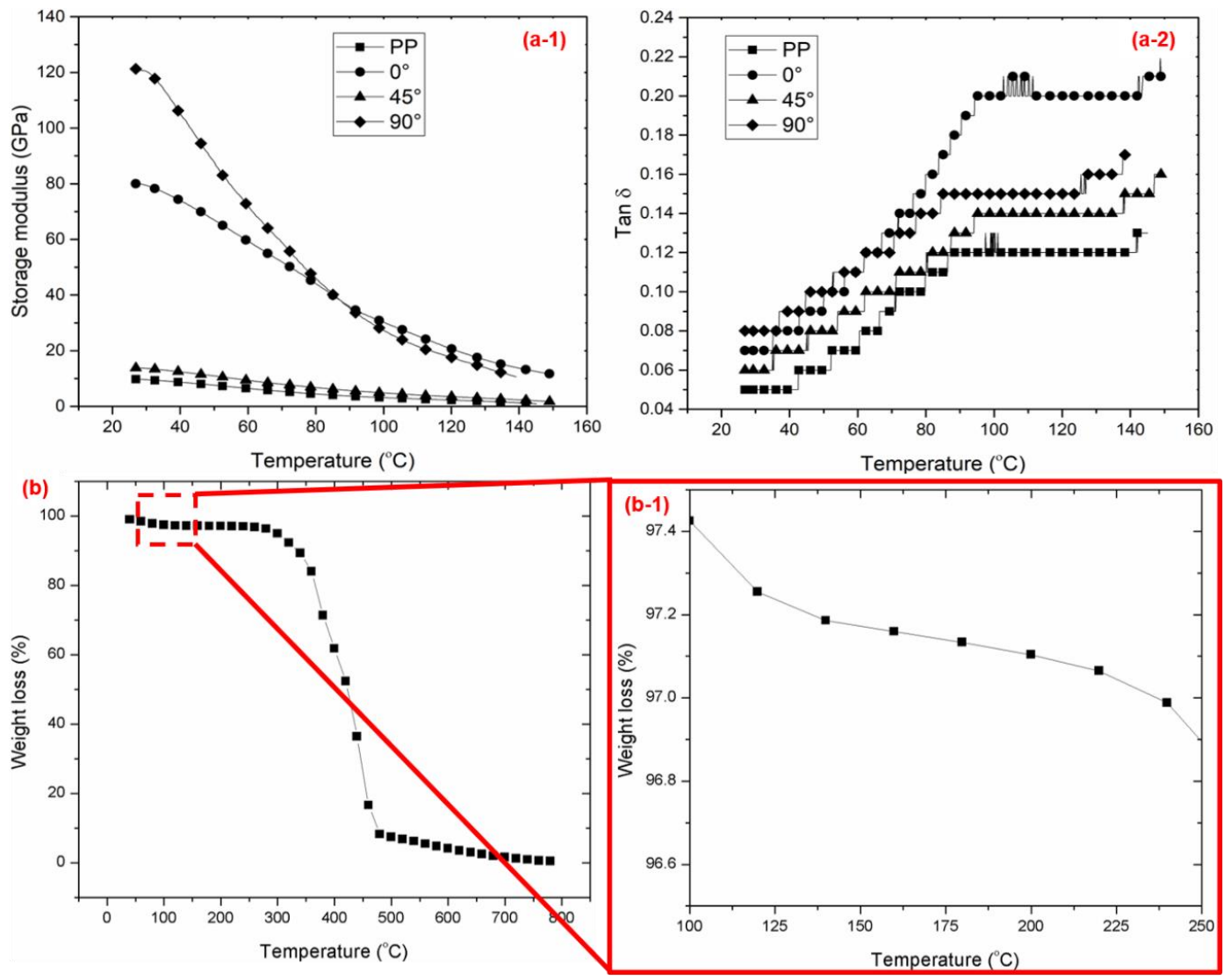

Figure 6. Dynamic mechanical analysis (DMA) of kenaf/PP composites. (a1) Storage modulus and (a2) $\tan \delta$ at a temperature range of 30 and $150{ }^{\circ} \mathrm{C}$, and (b) TGA of kenaf fibers; (b1) enlarged image of (b).
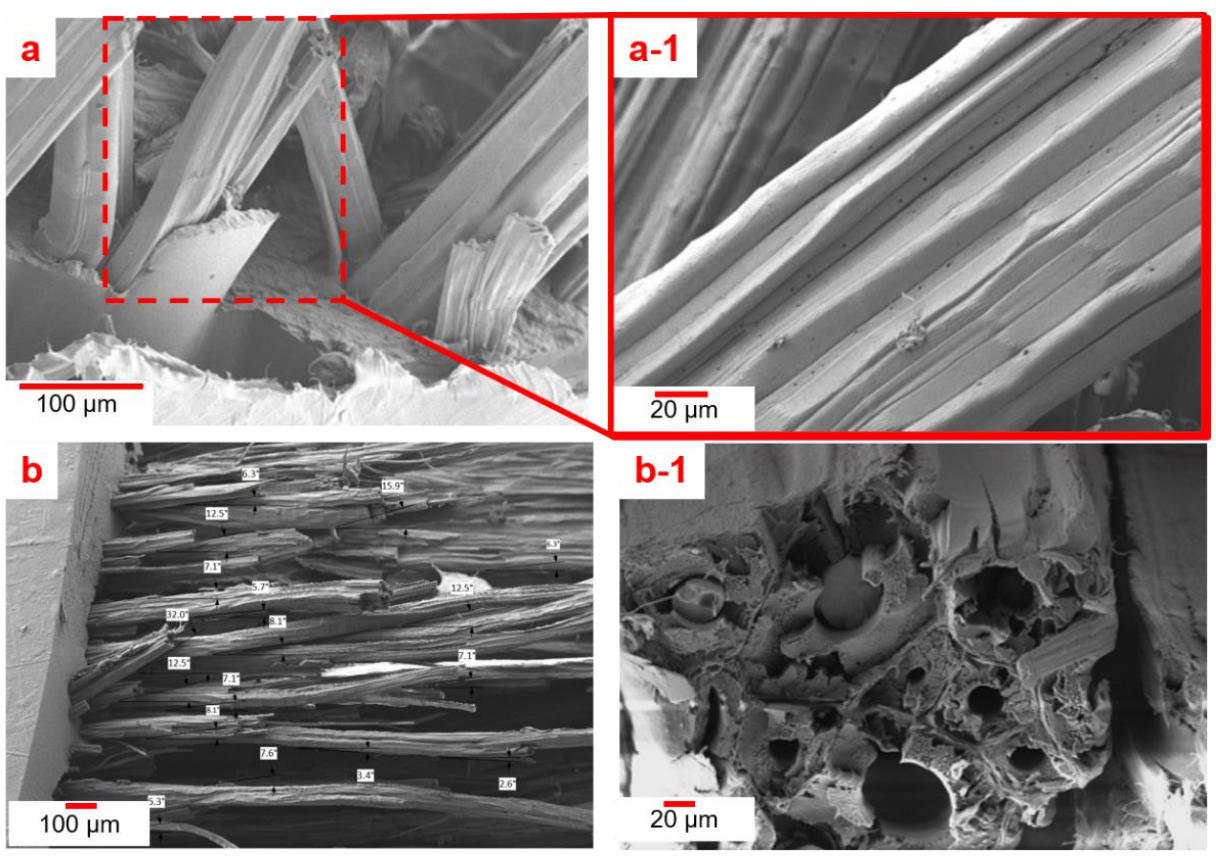

Figure 7. Images of (a) pulled-out kenaf fibers and (a1) smooth kenaf-fiber surface, (b) kenaf/PP composite at orientation angle of $90^{\circ}$, and (b1) kenaf/PP composite at orientation angle of $90^{\circ}$ (cross-section).

Figure 8 displays Poisson's ratio for the kenaf/PP composites, where the maximal values were obtained at orientation angles of $0^{\circ}$ and $90^{\circ}$, with 0.47 and 0.35 , respectively, at a temperature of $30^{\circ} \mathrm{C}$. 
At an orientation angle of $45^{\circ}$, the maximal Poisson's ratio was recorded at 0.47 at a temperature of $60^{\circ} \mathrm{C}$. Therefore, on the basis of the histogram results, the kenaf/PP composites at an orientation angle of $0^{\circ}$ attained the most consistent result, with no dramatic change, even though the temperature rose to $120^{\circ} \mathrm{C}$. This was in contrast with kenaf/PP composites at orientation angles of $45^{\circ}$ and $90^{\circ}$, which experienced a dramatic drop as temperature increased to $120^{\circ} \mathrm{C}$. These findings were supported by previous studies of epoxy resin, which reported that Poisson's ratio increased at a marginally lower temperature [48]. Therefore, on this basis, the composite at an orientation angle of $0^{\circ}$ offered similar elasticity behavior to that of pure PP. This indicated that kenaf/PP composites can attain high mechanical strength, as proven in the tensile-strength results (Figure 2). Furthermore, these findings also yielded excellent Poisson's ratio values, which were above the average obtained value (0.2-0.3) by other studies involving kenaf/polypropylene materials.

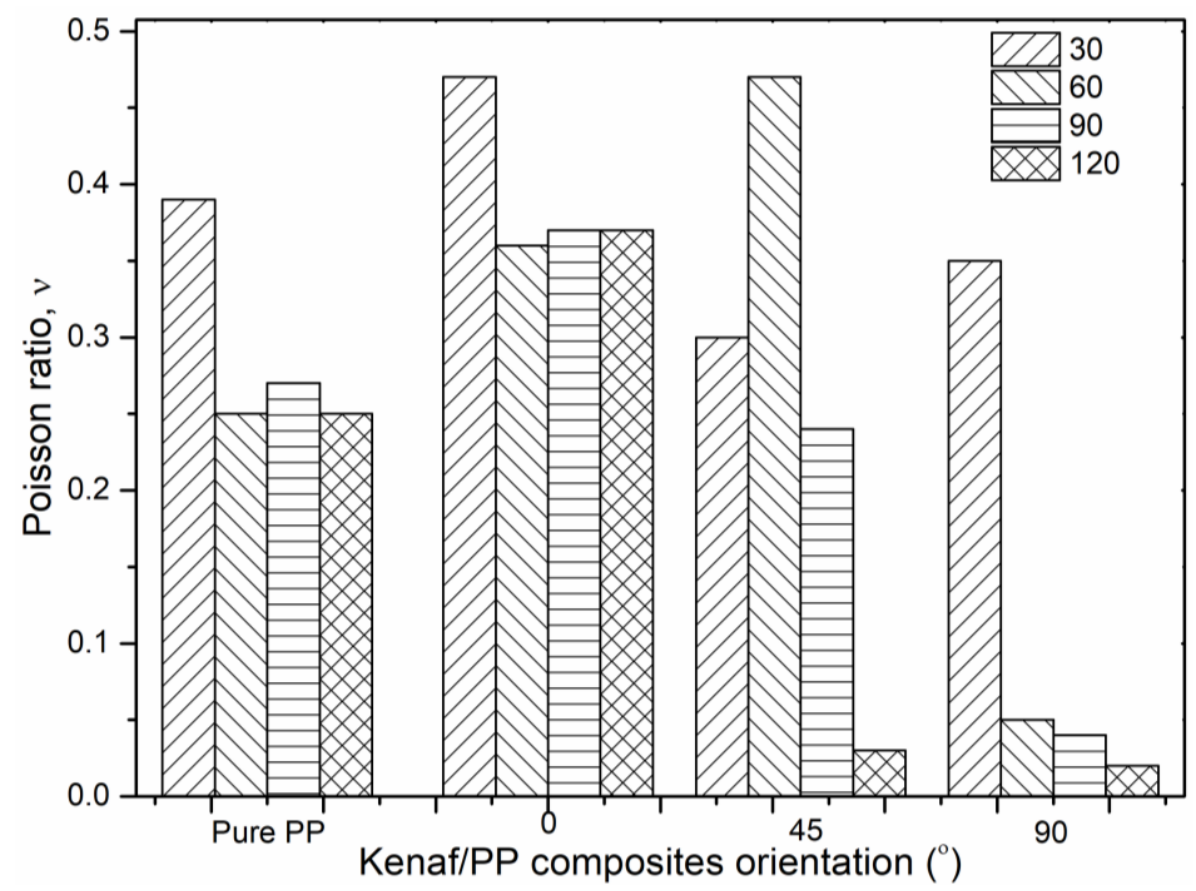

Figure 8. Poisson's ratio results of kenaf/polypropylene (PP) composites at various temperatures and orientation angles.

\section{Conclusions}

This study investigated aligned kenaf/PP composites at orientation angles between $0^{\circ}, 45^{\circ}$, and $90^{\circ}$, and prepared through a combing process at temperatures ranging from 30 to $120^{\circ} \mathrm{C}$. The findings indicated that the aligned kenaf fibers at an orientation angle of $0^{\circ}$ demonstrated excellent mechanical properties, with a tensile strength of $\sim 90 \mathrm{MPa}$ at a temperature of $120^{\circ} \mathrm{C}$. These findings were supported by the flexural-strength results, in which fibers at an orientation angle of $0^{\circ}$ obtained $\sim 50 \mathrm{MPa}$, which was above the average value ( $\sim 30 \mathrm{MPa})$ of a commercial automotive product at a temperature of 120 ${ }^{\circ} \mathrm{C}$. Accordingly, the study found that the mechanical properties of fabricated kenaf/PP composites aligned at an orientation angle of $0^{\circ}$ were able to exceed those of commercial products in today's market. Therefore, these results demonstrated that kenaf/PP composites have so much to offer in terms of affordability, excellent mechanical properties relating to safety issues, and lightweight components, especially in automotive applications. The development structure and kenaf-fiber content should be addressed, along with the calculation of the volume-void content, in future investigations.

Author Contributions: Conceptualization, A.B.S., N.M., and C.H.C.H.; methodology and validation, D.T.; formal analysis and investigation, D.T. and N.A.M.R.; writing-original-draft preparation, N.A.M.R. and A.B.S.; writing-review and editing, N.A.M.R.; supervision and project administration, A.B.S., N.M. and C.H.C.H.; funding acquisition, A.B.S. All authors have read and agreed to the published version of the manuscript. 
Funding: This research was funded by the Center for Research and Instrumentation Management (CRIM), Universiti Kebangsaan Malaysia, grant number DIP-2017-001.

Acknowledgments: The authors wish to express their gratitude and appreciation to the Center for Research and Instrumentation Management (CRIM), Universiti Kebangsaan Malaysia for its financial support under grant number DIP-2017-001, which enabled them to complete this study.

Conflicts of Interest: The authors declare no conflict of interest.

\section{References}

1. Yahya, M.N.; Daniel, D.; Chin, V.S.; Kamarudin, S.H.; Chuah, L. The potential of natural fibres for automotive sector-review. In Proceedings of CAR2017 International Congress of Automotive and Transport Engineering-Mobility Engineering and Environment, Pitesti, Romania, 8-10 November 2017; IOP Conference Series: Materials Science and Engineering. IOPScience: Bristol, UK, 2017; pp. 1-11.

2. Sanyang, M.L.; Ilyas, R.A.; Sapuan, S.M.; Jumaidin, R. Sugar palm starch-based composites for packaging applications. Bionanocompos. Packag. Appl. 2017, 125-147. [CrossRef]

3. Ilyas, R.A.; Sapuan, S.M.; Ishak, M.R.; Zainudin, E.S. Sugar palm nanofibrillated cellulose (Arenga pinnata (Wurmb.) Merr): Effect of cycles on their yield, physic-chemical, morphological and thermal behavior. Int. J. Biol. Macromol. 2019, 123, 379-388. [CrossRef] [PubMed]

4. D’Urso, L.; Spadaro, S.; Bonsignore, M.; Santangelo, S.; Compagnini, G.; Neri, F.; Fazio, E. Zinc oxide nanocolloids prepared by picosecond pulsed laser ablation in water at different temperatures. EPJ Web Conf. 2018, 167, 1-5. [CrossRef]

5. Ilyas, R.A.; Sapuan, S.M.; Ishak, M.R.; Zainudin, E.S. Development and characterization of sugar palm nanocrystalline cellulose reinforced sugar palm starch bionanocomposites. Carbohydr. Polym. 2018, 202, 186-202. [CrossRef]

6. Ilyas Rushdana, A.; Sapuan Salit, M.; Lamin Sanyang, M.; Ridzwan Ishak, M. Nanocrystalline Cellulose As Reinforcement For Polymeric Matrix Nanocomposites And Its Potential Applications: A Review. Curr. Anal. Chem. 2018, 14, 203-225. [CrossRef]

7. Pickering, K.L.; Efendy, M.G.A.; Le, T.M. A review of recent developments in natural fibre composites and their mechanical performance. Compos. Part A Appl. Sci. Manuf. 2016, 83, 98-112. [CrossRef]

8. Ariawan, D.; Salim, M.S.; Mat, R.; Ahmad, M.Z.; Zainal, T.; Ishak, A.M. Durability of alkali and heat treated kenaf fiber/unsaturated polyester composite fabricated by resin transfer molding under natural weathering exposure. Adv. Polym. Technol. 2018, 37, 1420-1434. [CrossRef]

9. Zampaloni, M.; Pourboghrat, F.; Yankovich, S.A.; Rodgers, B.N.; Moore, J.; Drzal, L.T.; Mohanty, A.K.; Misra, M. Kenaf natural fiber reinforced polypropylene composites: A discussion on manufacturing problems and solutions. Compos. Part A Appl. Sci. Manuf. 2007, 38, 1569-1580. [CrossRef]

10. Prakash, V.A.; Viswanthan, R. Fabrication and Characterization of Echinoidea spike Particles and Kenaf Natural Fibre-Reinforced Azadirachta-Indica Blended Epoxy Multi-hybrid Bio Composite. Compos. Part A 2019, 118, 317-326. [CrossRef]

11. Ramesh, M. Kenaf (Hibiscus cannabinus L.) fibre based bio-materials: A review on processing and properties. Prog. Mater. Sci. 2016, 78, 1-92. [CrossRef]

12. Wambua, P.; Ivens, J.; Verpoest, I. Natural fibres: Can they replace glass in fibre reinforced plastics? Compos. Sci. Technol. 2003, 63, 1259-1264. [CrossRef]

13. Fairuz, A.M.; Sapuan, S.M.; Marliana, N.M.; Sahari, J. 5. Fabrication and Effect of Immersion in Various Solutions on Mechanical Properties of Pultruded Kenaf Fiber Composites: A Review; Elsevier Ltd.: Amsterdam, The Netherlands, 2018; ISBN 9780081021606.

14. Ilyas, R.A.; Sapuan, S.M.; Ishak, M.R. Isolation and characterization of nanocrystalline cellulose from sugar palm fibres (Arenga Pinnata). Carbohydr. Polym. 2018, 181, 1038-1051. [CrossRef]

15. Razak, Z.; Bakar, A.; Muhamad, N.; Hassan, C.; Haron, C.; Khairul, M.; Radzi, F.; Farhani, N.; Tholibon, D.; Tharazi, I. Effects of thermal cycling on physical and tensile properties of injection moulded kenaf/carbon nanotubes/polypropylene hybrid composites. Compos. Part B 2019, 168, 159-165. [CrossRef]

16. Mansor, M.R.; Sapuan, S.M.; Zainudin, E.S.; Nuraini, A.A.; Hambali, A. Conceptual design of kenaf fiber polymer composite automotive parking brake lever using integrated TRIZ-Morphological Chart-Analytic Hierarchy Process method. Mater. Des. 2014, 54, 473-482. [CrossRef] 
17. Tholibon, D.; Sulong, A.B.; Muhammad, N.; Ismail, N.F.; Tharazi, I.; Radzi, M.K.F.M. Tensile properties of unidirectional kenaf fiber polypropylene composite. J. Teknol. 2016, 78, 101-106. [CrossRef]

18. Sulong, A.B.S.; Radzuan, N.A.M.; Mamat, M.R.; Tharazi, I.; Tholibon, D.; Dweiri, R.; Hammadi, M.S. Kenaf Reinforced PLA Composite Thermoforming: A Numerical Simulation. Int. J. Integr. Eng. 2019, 10, 15-20. [CrossRef]

19. Barton, R.L.; Keith, J.M.; King, J.A. Development and modeling of electrically conductive carbon filled liquid crystal polymer composites for fuel cell bipolar plate applications. J. New Mater. Electrochem. Syst. 2007, 10, 225.

20. Ilyas, R.A.; Sapuan, S.M.; Ishak, M.R.; Zainudin, E.S. Effect of delignification on the physical, thermal, chemical, and structural properties of sugar palm fibre. BioResources 2017, 12, 8734-8754. [CrossRef]

21. Radzuan, N.A.M.; Sulong, A.B.; Somalu, M.R. Influence the filler orientation on the performance of bipolar plate. Sains Malays. 2019, 48, 669-676. [CrossRef]

22. Asumani, O.M.L.; Reid, R.G.; Paskaramoorthy, R. The effects of alkali-silane treatment on the tensile and flexural properties of short fibre non-woven kenaf reinforced polypropylene composites. Compos. Part A Appl. Sci. Manuf. 2012, 43, 1431-1440. [CrossRef]

23. Hao, A.; Zhao, H.; Chen, J.Y. Kenaf/polypropylene nonwoven composites: The influence of manufacturing conditions on mechanical, thermal, and acoustical performance. Compos. Part B Eng. 2013, 54, 44-51. [CrossRef]

24. Radzuan, N.A.M.; Zakaria, M.Y.; Sulong, A.B.; Sahari, J. The effect of milled carbon fibre filler on electrical conductivity in highly conductive polymer composites. Compos. Part B Eng. 2017, 110, 153-160. [CrossRef]

25. Kiran, E.; Gillham, J.K. Pyrolysis-molecular weight chromatography: A new on-line system for analysis of polymers. II. Thermal decomposition of polyolefins: Polyethylene, polypropylene, polyisobutylene. J. Appl. Polym. Sci. 1976, 20, 2045-2068. [CrossRef]

26. Mariod, A.A.; Mirghani, M.E.S.; Hussein, I.H. Hibiscus cannabinus. In Unconventional Oilseeds and Oil Sources; Academic Press: Cambridge, MA, USA; International Islamic University: Selangor, Malaysia, 2017; pp. 45-51. ISBN 9780128094358.

27. Placet, V. Characterization of the thermo-mechanical behaviour of Hemp fibres intended for the manufacturing of high performance composites. Compos. Part A Appl. Sci. Manuf. 2009, 40, 1111-1118. [CrossRef]

28. Oksman, K.; Mathew, A.P.; Långström, R.; Nyström, B.; Joseph, K. The influence of fibre microstructure on fibre breakage and mechanical properties of natural fibre reinforced polypropylene. Compos. Sci. Technol. 2009, 69, 1847-1853. [CrossRef]

29. Jespersen, K.M.; Zangenberg, J.; Lowe, T.; Withers, P.J.; Mikkelsen, L.P. Fatigue damage assessment of uni-directional non-crimp fabric reinforced polyester composite using X-ray computed tomography. Compos. Sci. Technol. 2016, 136, 94-103. [CrossRef]

30. Pötschke, P.; Bhattacharyya, A.R.; Janke, A. Melt mixing of polycarbonate with multiwalled carbon nanotubes: Microscopic studies on the state of dispersion. Eur. Polym. J. 2004, 40, 137-148. [CrossRef]

31. Herrera-Franco, P.J.; Valadez-González, A. Mechanical properties of continuous natural fibre-reinforced polymer composites. Compos. Part A Appl. Sci. Manuf. 2004, 35, 339-345. [CrossRef]

32. Taufiq, M.J.; Mansor, M.R.; Mustafa, Z. Characterisation of wood plastic composite manufactured from kenaf fibre reinforced recycled-unused plastic blend. Compos. Struct. 2018, 189, 510-515. [CrossRef]

33. Afiqah, N.; Radzuan, M.; Sulong, A.B.; Irwan, M.; Firdaus, M.; Husaini, T.; Majlan, E.H. Fabrication of multi-filler MCF/MWCNT/SG-based bipolar plates. Ceram. Int. 2019, 45, 7413-7418. [CrossRef]

34. Radzuan, N.A.M.; Sulong, A.B.; Somalu, M.R.; Majlan, E.H.; Husaini, T.; Rosli, M.I. Effects of Die Configuration on the Electrical Conductivity of Polypropylene Reinforced Milled Carbon Fibers: An Application on a Bipolar Plate. Polymers 2018, 10, 558. [CrossRef]

35. Tungjitpornkull, S.; Sombatsompop, N. Processing technique and fiber orientation angle affecting the mechanical properties of E-glass fiber reinforced wood/PVC composites. J. Mater. Process. Technol. 2009, 209, 3079-3088. [CrossRef]

36. Abral, H.; Basri, A.; Muhammad, F.; Fernando, Y.; Hafizulhaq, F.; Mahardika, M.; Sugiarti, E.; Sapuan, S.M.; Ilyas, R.A.; Stephane, I. A simple method for improving the properties of the sago starch films prepared by using ultrasonication treatment. Food Hydrocoll. 2019, 93, 276-283. [CrossRef]

37. Huang, M.; Tai, C. The effective factors in the warpage problem of an injection-molded part with a thin shell feature. J. Mater. Process. Technol. 2001, 110, 1-9. [CrossRef] 
38. Chen, C.-P.; Chuang, M.-T.; Hsiao, Y.-H.; Yang, Y.-K.; Tsai, C.-H. Simulation and experimental study in determining injection molding process parameters for thin-shell plastic parts via design of experiments analysis. Expert Syst. Appl. 2009, 36, 10752-10759. [CrossRef]

39. Karian, H.G. Handbook of Polypropylene and Polypropylene Composites, Revised and Expanded, 2nd ed.; CRC Press: Boca Raton, NY, USA, 2003; ISBN 0-8247-4064-5.

40. Bachtiar, D.; Sapuan, S.M.; Hamdan, M.M. Flexural properties of alkaline treated sugar palm fibre reinforced epoxy composites. Int. J. Automot. Mech. Eng. 2010, 1, 79-90. [CrossRef]

41. Akhtar, M.N.; Sulong, A.B.; Radzi, M.K.F.; Ismail, N.F.; Raza, M.R.; Muhamad, N.; Khan, M.A. Influence of alkaline treatment and fiber loading on the physical and mechanical properties of kenaf/polypropylene composites for variety of applications. Prog. Nat. Sci. Mater. Int. 2016, 26, 657-664. [CrossRef]

42. Houshyar, S.; Shanks, R.A.; Hodzic, A. Effect of Fibre-Orientation on Mechanical Properties of Polypropylene Composites. In Composite Technologies for 2020; Ye, L., Mai, Y.W., Su, Z., Eds.; Woodhead Publishing: Melbourne, Australia, 2004; pp. 41-45. ISBN 978-1-85573-831-7.

43. Mutasher, S.A.; Poh, A.; Than, A.M.; Law, J. The Effect of Alkali Treatment Mechanical Properties of Kenaf Fiber Epoxy Composite. Key Eng. Mater. 2011, 471-472, 191-196. [CrossRef]

44. Baghaei, B.; Skrifvars, M.; Salehi, M.; Bashir, T.; Rissanen, M.; Nousiainen, P. Novel aligned hemp fibre reinforcement for structural biocomposites: Porosity, water absorption, mechanical performances and viscoelastic behaviour. Compos. Part A Appl. Sci. Manuf. 2014, 61, 1-12. [CrossRef]

45. Saba, N.; Jawaid, M.; Alothman, O.Y.; Paridah, M.T. A review on dynamic mechanical properties of natural fibre reinforced polymer composites. Constr. Build. Mater. 2016, 106, 149-159. [CrossRef]

46. Mohd Radzuan, N.A.; Tholibon, D.; Sulong, A.B.; Muhamad, N.; Haron, C.H.C. New processing technique for biodegradable kenaf composites: A simple alternative to commercial automotive parts. Compos. Part B Eng. 2020, 184, 107644. [CrossRef]

47. El-Shekeil, Y.A.; Sapuan, S.M.; Abdan, K.; Zainudin, E.S. Influence of fiber content on the mechanical and thermal properties of Kenaf fiber reinforced thermoplastic polyurethane composites. Mater. Des. 2012, 40, 299-303. [CrossRef]

48. Pandini, S.; Pegoretti, A. Time, Temperature, and Strain Effects on Viscoelastic Poisson's Ratio of Epoxy Resins. Polym. Eng. Sci. 2008, 48, 1434-1441. [CrossRef] 